\title{
Loading Posture Control in Anterior and Posterior Positions Using SEBT
}

\author{
Huiyu Zhou ${ }^{1,}$ a , Siqin Shen ${ }^{1}$ and Yaodong Gu ${ }^{1}$ \\ ${ }^{1}$ Faculty of Sports Science, Ningbo University, Ningbo, China 315211 \\ a zhouhuiyunb@qq.com
}

\begin{abstract}
Keywords: Balance; Anterior position; Posterior position; Star Excursion Balance Test; Normalized excursion distance
\end{abstract}

\begin{abstract}
Objective: The Star Excursion Balance Test (SEBT) is a valid method to measure dynamic balance. Load carriage in anterior and posterior positions would have different balance control ability. Methods: Twenty healthy young males were volunteered to this experiment and performed SEBT with load carriage in anterior and posterior positions in $0 \%, 5 \%, 10 \%, 15 \%$ and $20 \%$ body weight loads. Vicon system and MATLAB software were used to calculate the result of SEBT. ICC and One-way Analysis of Variance (ANOVA) with repeated measures analysed the variation tendency and one-way ANOVA analysed the differences between each condition. Results: The normalized excursion distance (\%) has decreasing trends with the increase of loads no matter anterior or posterior positions. Load carriage would cause balance disturbances. However, posterior position shows significant decreasing trends while anterior position shows modest decreasing trends. In addition, anterior positions show larger results of SEBT than posterior positions among almost all the conditions. It indicated that anterior positions have higher balance control ability than posterior positions. Conclusion: From the Cyto Scape-web which is used to show the differences between each weight of loads, $0 \%$ and $5 \%$ loads indicate significant differences compare with other loads in posterior position. On the other hand, $0 \%$ and $20 \%$ loads show significant differences in anterior position. It observed that above $5 \%$ loads were affect balance control ability for load carriage in posterior position and below $20 \%$ loads was the avoidable weight to anterior position. This study provides new measure to test the dynamic balance during load carriage. Load carriage would cause injury due to overbalance, anterior position has higher risk than posterior position.
\end{abstract}

\section{Introduction}

The Star Excursion Balance Test (SEBT) is a normal and valid outcome measure to check dynamic balance. Gray developed this test as a rehabilitative tool and then it becomes a clinical use for athletic and pathologic populations [1]. It covers a range of fields including screening [2, 3], injury identification [4, 5], training and rehabilitation [6, 7, 8]. The Star Excursion Balance Test needs to perform how far they can reach without overbalance. This test requires individual to reach along a significant line with one lower limb while standing on the other lower limb [9]. The reaching distance is taken to be related with dynamic balance [10]. Farther distance reached suggests better dynamic postural-control. Due to the individual difference, the Star Excursion Balance Test do not have unified standard. Compared between uninjured and injured lower limbs or before and after treatment or intervention are the normal methods to analysis results [11]. The Star Excursion Balance Test also demands individual performed in the 8 reach directions. As it developed, three reach directions were recommended (anterior, posteromedial and posterolateral reaches were preserved) $[12,13]$. Gribble et al. [14]found these three directions has excellent reliability.

Load carriage is a normal weighted carry method used in recreational, military pursuits, and other fields $[15,16]$. Tzu-wei et al. [17] supported that load carriage could increase the work and metabolic cost. It is established that could raise the risk of injuries, joint problems and muscle strain whether posterior or anterior positions $[18,19]$. Load carriage in anterior positions is specified to distinguish it from posterior positions [20]. Chow et al. [21] indicated that a load carriage carried anteriorly might be responsible for postural changes. Load carriage is considered that could induce postural imbalance 
whether static and dynamic conditions due to shifting the posterior and superior the combined centre of mass of load carriage system (loads plus individual) [22, 23]. However, current studies have researched the load carriage on static balance or gait analysis. Very few studies have investigated the load carriage with other balance measurement. Moreover, load carriage in anterior position has been relatively unexplored.

Consequently, this study aimed to investigate the differences of balance control ability between anterior and posterior positions during load carriage. The SEBT was used to test the dynamic balance. It was hypothesised that increasing loads would have a variation tendency of the Star Excursion Balance Test results and that different load carriage positions (anterior and posterior) could change the performance of the Star Excursion Balance Test.

\section{Methods}

Twenty young healthy males participated in this experiment. All of them were Ningbo University students. Table 1 listed the personal information. They were free from injury and pain. In addition, there were no large surgery in the past six months. In order to check the health condition and balance order, all the participants completed patient reported outcome measures including Tegner Activity Level Scale [24], Lower Extremity Functional Scale (LEFS) [25], Visual Analog Scale (VAS). Results are provided in Table 1 and all the participants were qualified.

Table 1 Participant demographics

\begin{tabular}{cc}
\hline & Total \\
\hline Participants & 20 \\
Age (years) & $25.0 \pm 2.1$ \\
Height $(\mathrm{cm})$ & $176.0 \pm 2.3$ \\
Weight $(\mathrm{kg})$ & $64.0 \pm 5.5$ \\
Right leg length $(\mathrm{cm}) *$ & $90.5 \pm 4.2$ \\
Body mass index & $22.42 \pm 2.0$ \\
LEFS score & $78.5 \pm 2.1$ \\
Tegner activity score & $6.0 \pm 1.0$ \\
VAS & $0.0 \pm 0.0$ \\
\hline
\end{tabular}

The 8-camera Vicon motion analysis system (Oxford Metric Ltd, Oxford, UK) was used to capture the three-dimensional coordinates at the frequency of $200 \mathrm{~Hz}$. Participants were unified to wear a pair of running tights and lightweight sports shoes. Three reflective points (diameter $14 \mathrm{~mm}$ ) were attached with adhesive on the left lower limbs over anatomical landmarks including: lateral malleolus, second metatarsal head and calcaneus (Fig. 1-C).
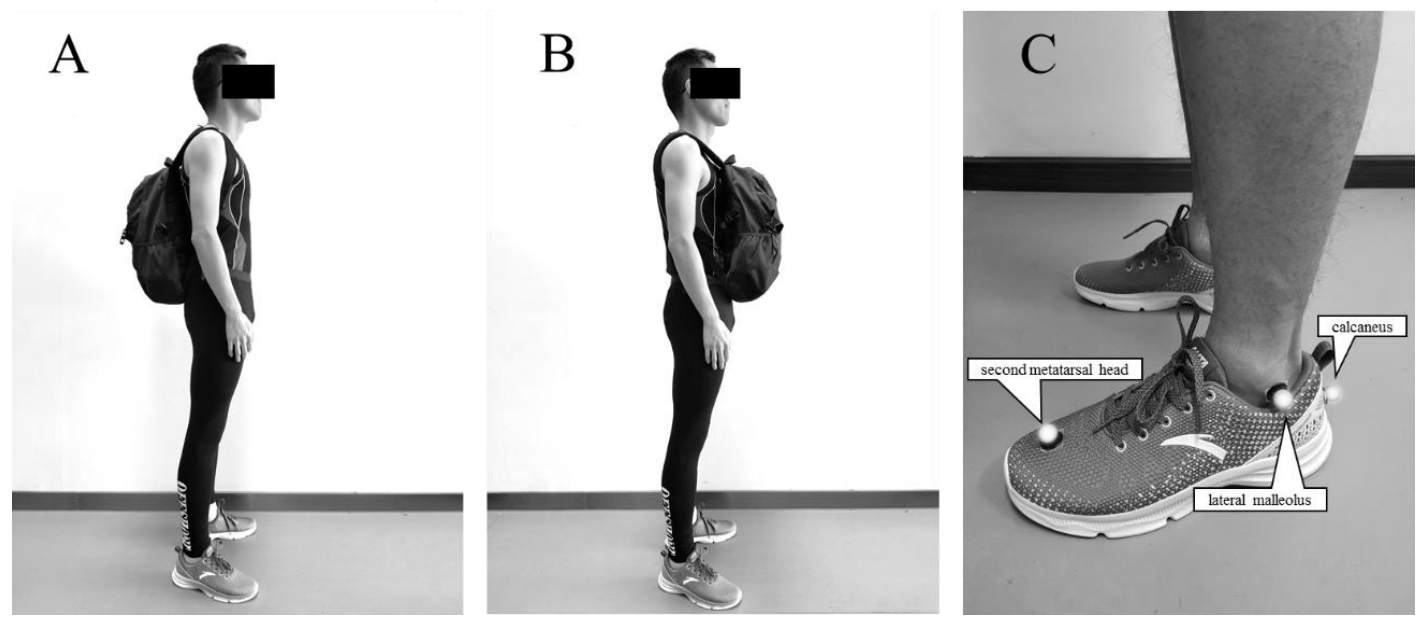

Figure 1. Posterior position (A), anterior position (B) and three reflective points (C) 
There were three significant lines extending at $120^{\circ}$ increments from the center. The Vicon system was placed around the center to record the motion of marked points. According to the report of Robinson et al [26], each participant practised four times to know the SEBT before the experiment. Coughlan et al [27] indicated that there were no significant differences between right and left lower limbs. Therefore, right lower limb was set as stance limb and left lower limb was the free limb.

Based on the researches of Star Excursion Balance Test before, this study is following the previously experiments of Star Excursion Balance Test [28]. Participant was required to stand in the center of three lines and orient anteriorly. Individual reached with the free limb in the anterior, posteromedial and posterolateral directions as far as possible while stance limb was still at the origin. Then free limb touched down lightly and came back. The process completed continuously without compromising equilibrium. Individuals were asked to place their hands on their hips and not allowed lift the stance heel off the ground during the test.

Weight of loads were set in four conditions: 5\%, 10\%, 15\% and 20\% BW (body weight). Each participant performed five times successfully for each loads condition in posterior positions (Fig. 1-A) and anterior positions (Fig.1-B). The loads conditions in two load carriage positions and testing directions were randomised to prevent order effects. A minimum of $45 \mathrm{~s}$ was allowed between trials to avoid fatigue.

Vicon System recorded the three-dimensional coordinates of the reflective points during the SEBT process. Based on the z-axis of lateral malleolus, second metatarsal head and calcaneus marker point, starting and landing coordinates were founded. (i.e.: Fig. 2 shows the landing time of anterior directions when three marker point stop moving during touching).

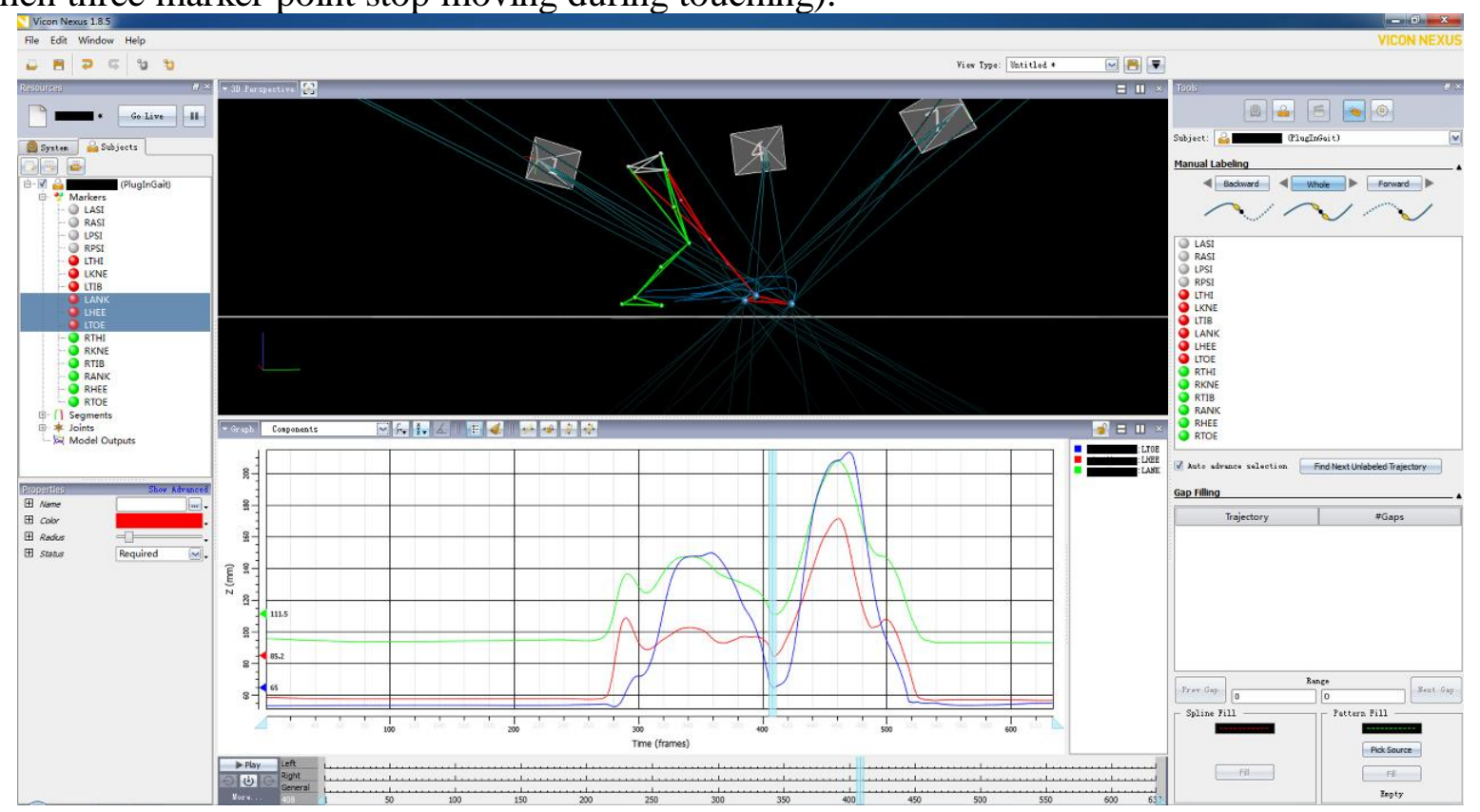

Figure 2. Procedure of Vicon System during finding landing point in anterior direction

\section{Results}

The Star Excursion Balance Test is the common method to measure the dynamic balance ability. From Table 2, the normalized excursion distance (\%) of SEBT shows significant decreasing trends (all the | ICC | =0.70-0.90, level: Good; $\mathrm{p}<.01$ ) among three reaching directions during load carriage in posterior position. The results of SEBT show modest decreasing trends ( all the $\mid$ ICC $\mid=0.40-0.70$, level: Fair; $\mathrm{p}<.01$ ) among all the reaching directions when load carriage in anterior position. From the result, dynamic balance reduced with the increase of loads whether anterior or posterior positions. Previous study supported that the work and metabolic cost could increase while added loads. Some studies also reported that higher impact force could overstimulate plantar mechanoreceptors while the 
quality of sensory information decrease. This could lead to balance disturbances. These researches all supported that the increase of loads was responsible for the instability.

Table 2 Variation tendency of Star Excursion Balance Test between posterior and anterior positions

\begin{tabular}{ccc}
\hline & $I C C$ & $P$ \\
\hline & Posterior position & \\
Anterior reach & -0.724 & $<.01$ \\
Posteromedial reach & -0.762 & $<.01$ \\
Posterolateral reach & -0.788 & $<.01$ \\
& Anterior position & \\
Anterior reach & -.0629 & $<.01$ \\
Posteromedial reach & -0.487 & $<.01$ \\
Posterolateral reach & -0.701 & $<.01$ \\
\hline
\end{tabular}

\section{Conclusion}

Load carriage in anterior and posterior positions show different results in different SEBT normalized excursion distances. The normalized excursion distance decreases as weight of loads increase for three reaching directions. The load carriage in anterior position has higher normalized excursion distance than the posterior position. In addition, with the increase of loads, load carriage in posterior position shows plummet at 5\%, while the anterior positions rapid decreases at $20 \%$. This finding suggests that $5 \%$ and $20 \%$ loads were the optimal weight loads for posterior and anterior positions respectively. Load carriage could cause injury because of overbalance and posterior position might have higher risk of injury than anterior position.

\section{References}

[1] P.A. Gribble, S.E. Kelly, K.M. Refshauge, C.E. Hiller, Interrater reliability of the star excursion balance test, Journal of athletic training. 48 (2013) 621-626.

[2] K. Sato, M. Mokha, Does core strength training influence running kinetics, lower-extremity stability, and 5000-M performance in runners, The Journal of Strength \& Conditioning Research. 23(2009) 133-140.

[3] P.T. Glenna Batson ,Validating a dance-specific screening test for balance: preliminary results from multisite testing, Medical problems of performing artists. 25(2010) 110.

[4] J.M. Sefton, C.A. Hicks-Little, TJ. Hubbard, M.G.Clemens, C.M. Yengo, D.M. Koceja, M.L. Cordova, Sensorimotor function as a predictor of chronic ankle instability, Clinical Biomechanics. 24(2009) 451-458.

[5] L. Herrington, J. Hatcher, A. Hatcher, M. McNicholas, A comparison of Star Excursion Balance Test reach distances between ACL deficient patients and asymptomatic controls, The Knee. 16(2009) 149-152.

[6] T.C. Mcleod, T. Armstrong, M. Miller, J.L. Sauers, Balance improvements in female high school basketball players after a 6-week neuromuscular-training program, Journal of Sport Rehabilitation. 18(2009) 465-81.

[7] T.C. Eisen, J.V. Danoff, J.E. Leone, T.A. Miller, The effects of multiaxial and uniaxial unstable surface balance training in college athletes, The Journal of Strength \& Conditioning Research. 24(2010) 1740-1745.

[8] A. Filipa, R. Byrnes, M.V. Paterno, G.D. Myer, T.E. Hewett, Neuromuscular training improves performance on the star excursion balance test in young female athletes, Journal of orthopaedic \& sports physical therapy. 40(2010) 551-558. 
[9] K. Fullam, B. Caulfield, G.F. Coughlan, E. Delahunt, Kinematic analysis of selected reach directions of the Star Excursion Balance Test compared with the Y-Balance Test, Journal of sport rehabilitation. 23(2014) 27-35.

[10]P.A. Gribble, J. Hertel, P. Plisky, Using the Star Excursion Balance Test to assess dynamic postural-control deficits and outcomes in lower extremity injury: a literature and systematic review, Journal of athletic training. 47(2012) 339-357.

[11]P.A. Gribble, S.E. Kelly, K.M. Refshauge, C.E. Hiller, Interrater reliability of the star excursion balance test, Journal of athletic training. 48(2013) 621-626.

[12] J. Hertel, R.A. Braham, S.A. Hale, L.C. Olmsted-Kramer, Simplifying the star excursion balance test: analyses of subjects with and without chronic ankle instability, Journal of Orthopaedic \& Sports Physical Therapy. 36(2006) 131-137.

[13]J. Hertel, Sensorimotor deficits with ankle sprains and chronic ankle instability, Clinics in sportsmedicine. 27(2008) 353-370.

[14]P.A. Gribble, S.E. Kelly, K.M. Refshauge, C.E. Hiller, Interrater reliability of the star excursion balance test. Journal of athletic training, 48 (2013) 621-626.

[15]R.M. Orr, V. Johnston, J. Coyle, R. Pope, Reported load carriage injuries of the Australian army soldier, Journal of occupational rehabilitation, 25(2015) 316-322.

[16]E.M. Strube, A. Sumner, R.O. Kollock Jr, K.E. Games, M.A. Lackamp, M. Mizutani, J.M.Sefton, The Effect of Military Load Carriage on Postural Sway, Forward Trunk Lean, and Pelvic Girdle Motion, International Journal of Exercise Science, 10(2017) 3.

[17] M. Castro, S. Abreu, H. Sousa, L. Machado, R. Santos, J.P. Vilas-Boas, Ground reaction forces and plantar pressure distribution during occasional loaded gait, Applied ergonomics, 44(2013) 503-509.

[18] Y. Feng, Y. Song, The Categories of AFO and Its Effect on Patients With Foot Impair: A Systemic Review. Physical Activity and Health, 1(2017) 8-16.

[19]T. Kim, E. Chai, Trunk and pelvic coordination at various walking speeds during an anterior load carriage task in subjects with and without chronic low back pain, Journal of Physical Therapy Science. 27(2015) 2353-2356.

[20]D. Kour, S. Sen, A. Dhawan, Variation in the kinematic response of cervical spine, proprioception and muscle activity during anterior load carriage-an experimental study, Journalof Novel Physiotherapies. 4(2014) 2.

[21]D.H.K. Chow, M.F. Li, A. Lai, M.H. Pope, Effect of load carriage on spinal compression, International Journal of Industrial Ergonomics. 41(2011) 219-223.

[22]T. Singh, M. Koh, Effects of backpack load position on spatiotemporal parameters and trunk forward lean, Gait \& posture. 29(2009) 49-53.

[23] M. Pau, M. Pau, Postural sway modifications induced by backpack carriage in primary school children: a case study in Italy, Ergonomics. 53(2010) 872-881.

[24] K.K Briggs, J. Lysholm, Y. Tegner, W.G. Rodkey, M.S. Kocher, J.R. Steadman, The reliability, validity, and responsiveness of the Lysholm score and Tegner activity scale for anterior cruciate ligament injuries of the knee 25 years later, The American journal of sports medicine. 37 (2009) 890-897.

[25]J.M. Binkley, P.W. Stratford, S.A. Lott, D.L. Riddle,. The lower extrenity functional scale (LEFS): Scale development, measurement properties, and clinical application, Physical therapy. 79(1999) 371.

[26]R.H. Robinson, P.A. Gribble, Support for a reduction in the number of trials needed for the star excursion balance test, Archives of physical medicine and rehabilitation. 89(2008) 364-370.

[27] G.F. Coughlan, K. Fullam, E. Delahunt, C. Gissane, B.M. Caulfield, A comparison between performance on selected directions of the star excursion balance test and the $\mathrm{Y}$ balance test, Journal of athletic training. 47(2012) 366-371.

[28]P.J. Plisky, M.J. Rauh, T.W. Kaminski, F.B. Underwood, Star Excursion Balance Test as a predictor of lower extremity injury in high school basketball players, Journal of Orthopaedic \& Sports Physical Therapy. 36(2006) 911-919. 
[29] G.F. Coughlan, K. Fullam, E. Delahunt, C. Gissane, B.M. Caulfield, A comparison between performance on selected directions of the star excursion balance test and the Y balance test, Journal of athletic training. 47(2012) 366-371.

[30]B. Zhang, S. Li, Y. Zhang, Evaluation of Dynamic Posture Control when Wearing High-Heeled Shoes Using Star Excursion Balance Test. Physical Activity and Health, 1(2017) 1-7. 